\title{
Site determination of friction in prestressing cables and interpretation of test data*
}

\author{
by E. G. Trimble, B.Sc.(Eng.), A.M.I.C.E., A.M.I.Struct.E.
}

ERRATA: In Table 2, on page 98, the values for "Calculated extension allowing for friction loss $1 \%$ (in.) "should read as follows:

$\begin{array}{ll}\text { E4 } & 2 \cdot 12 \\ \text { E6 } & 2 \cdot 26 \\ \text { E14 } & 2 \cdot 26 \\ \text { F4 } & 2 \cdot 21 \\ \text { F6 } & 2 \cdot 31 \\ \text { F14 } & 2 \cdot 24 \\ \text { G4 } & 2 \cdot 09 \\ \text { G6 } & 2 \cdot 14 \\ \text { G11 } & 2 \cdot 08 \\ \text { J4 } & 2 \cdot 09 \\ \text { J6 } & 2 \cdot 04 \\ \text { J11 } & 2 \cdot 01 \\ \text { J16 } & 2 \cdot 18\end{array}$

Contribution by W. M. Johns, M.C., B.Sc.(Eng.), M.I.C.E. (PSC Equipment Limited)

$\mathrm{Mr}$ Trimble's experiment is of interest from a number of points of view.

(1) The work on the characteristics of jacks confirms the usual assumption that friction in the cone and jack account for $200-300 \mathrm{lb} / \mathrm{in}^{2}$ of the pressure-gauge reading. To be more accurate than this is virtually of no value, because of the nature of site operations.

(2) The findings regarding friction in cables confirm those of Guyon in Chapter IV of his Prestressed Concrete. (1) The aggregate change of angle of the cables from end to end amounts to $90-100^{\circ}$ and will, of course, affect any type of prestressing cable. No doubt $\mathrm{Mr}$ Trimble will agree that the use of the type of cable which he chose required no special precautions to be taken by the contractor.

(3) The question of "taking up the slack" at the commencement of the stressing operation plays a big partparticularly in view of the double change of direction of curvature in each cable. This will be quite clear when it is appreciated that the slack in the central sag can only be taken up after breaking the static friction round the outer hog-curves of the cable; this is a vastly different proposition from taking up the slack in a cable with only a single curve, when the slack is taken up progressively from the centre outwards towards the jacks. I therefore venture to

\footnotetext{
*Pages 95-100.
}

suggest that distortion of the cable plays a very much smaller part than $\mathrm{Mr}$ Trimble suggests in the discrepancy between measured and calculated extensions.

The simple method which we normally recommend for ensuring that slack is fully taken up in cables with single curves could, I admit, not be used with any certainty in Mr Trimble's work (with treble curvature). I therefore agree that in such a case the guidance of the pressure gauge would be of more value than the extension reading. (4) There usually are variations in tension in different parts of a cable immediately after stressing. That the tension at the ends can be less than the tension elsewhere at this time is doubtless true; however, it has been apparent on a number of occasions that this variation is short-lived and I am confident that, if the author were able to check cable tensions at various points, say, 48 hours after stressing, he would find the variation remarkably smaller, possibly even non-existent. I therefore believe the prediction of variation of tension to have only a temporary value.

\section{REFERENCE}

1. GUYON, Y. Prestressed Concrete. 1st edition. London. Contractors Record and Municipal Engineering, 1953. pp. 84-94.

\section{Contribution by Professor R. G. Robertson} (University of Cape Town)

The writer was very glad to receive this paper confirming his own investigations regarding friction in prestressing cables, an account of which he had already dispatched to the Editor before Mr Trimble's paper was received in Cape Town.

Mr Trimble has made a very valuable contribution in his discovery of the discrepancy between the expected and the measured extensions with Freyssinet cables, and my own laboratory experiments confirmed this to some extent: I have been advocating the collection of such data here for some years past without much response from practising firms.

There appears, however, to be some discrepancy in Mr Trimble's calculated extensions in column 15 of Table 2. With the first cable, E4, it appears that, owing to the jack pull of $106,000 \mathrm{lb}$ and friction loss of $38 \%$, the central tension was $66,000 \mathrm{lb}$ and the mean tension $86,000 \mathrm{lb}$ : the area of section was $0.715 \mathrm{in}^{2}$ and the mean stress was $120,000 \mathrm{lb} / \mathrm{in}^{2}$. From column 14 the value of $E_{s}$ was $29 \times 10^{6} \mathrm{lb} / \mathrm{in}^{2}$ and from the mean tension, the calculated extension (subtracting an initial pull of $10,000 \mathrm{lb}$ ) should 
TABLE I

\begin{tabular}{|c|c|c|c|c|c|c|c|}
\hline $\begin{array}{c}\text { Curve } \\
\text { Radius (ft) }\end{array}$ & $\begin{array}{c}\text { Sinuous } \\
15\end{array}$ & $\begin{array}{c}\text { Sinuous } \\
25\end{array}$ & $\begin{array}{c}\text { Sinuous } \\
50\end{array}$ & $\begin{array}{l}\text { Continuous } \\
50\end{array}$ & $\begin{array}{c}\text { Sinuous } \\
100\end{array}$ & $\begin{array}{l}\text { Continuous } \\
100\end{array}$ & $\begin{array}{c}\text { Straight } \\
\alpha\end{array}$ \\
\hline \multicolumn{8}{|c|}{ Six loose wires } \\
\hline$Y$ & 0.0350 & $0 \cdot 0230$ & 0.0082 & 0.0133 & 0.0050 & 0.0046 & 0.0017 \\
\hline $\begin{array}{l}\text { Measured } \\
\text { extension } / P_{o} \\
\end{array}$ & 0.083 & 0.093 & $0 \cdot 114$ & 0.099 & - & 一 & 一 \\
\hline $\begin{array}{l}\text { Calculated } \\
\text { extension } / P_{o}\end{array}$ & 0.071 & 0.084 & $0 \cdot 105$ & $0 \cdot 098$ & $0 \cdot 113$ & $0 \cdot 113$ & $0 \cdot 119$ \\
\hline Ratio of last two & $1 \cdot 17$ & $I \cdot 11$ & 1.09 & $1 \cdot 01$ & - & - & - \\
\hline & \multicolumn{5}{|c|}{ Four wires with spacers } & & \\
\hline$\gamma$ & $0 \cdot 0147$ & 0.0093 & $0 \cdot 0029$ & $0 \cdot 0040$ & 0.0021 & 0.0018 & 0 \\
\hline Ratio to $\gamma$ above & 0.42 & 0.40 & $0 \cdot 35$ & $0 \cdot 30$ & 0.42 & $0 \cdot 39$ & 0 \\
\hline $\begin{array}{l}\text { Measured } \\
\text { extension } / P_{o}\end{array}$ & $0 \cdot 132$ & - & $0 \cdot 158$ & $0 \cdot 158$ & 一 & $一$ & 一 \\
\hline $\begin{array}{l}\text { Calculated } \\
\text { extension } / P_{o}\end{array}$ & $0 \cdot 129$ & $0 \cdot 141$ & $0 \cdot 159$ & $0 \cdot 155$ & $0 \cdot 156$ & 0.159 & $0 \cdot 166$ \\
\hline Ratio of last two & $1 \cdot 02$ & - & 0.99 & 1.02 & - & - & - \\
\hline
\end{tabular}

have been $\frac{96}{106} \times 2.38$ in. $=2.15$ in., and not 1.66 in. as given. With Mr Trimble's figure, the mean cable tension was only $71,000 \mathrm{lb}$; this could not be correct if the friction loss was $38 \%$. For a cable tensioned from one end, the calculated extension might be 1.66 in., but this should not be confused with extension measured with jacking at both ends.

The discrepancy between the measured extension $(2.5$ in.) and that calculated (possibly $2 \cdot 15 \mathrm{in}$.) was in any case sufficient to suggest that inefficient wire spacers were being used. Efficient spacers such as drilled washers halve the friction, and should pay for their use handsomely. (See Table I.)

Mr Trimble presumably used a coiled wire core spacer, and Guyon's tests indicated that this type of spacer actually increased the friction. Mr Trimble does not mention the friction coefficients used in checking the extensions. It appears that $y$. must have been at least $0 \cdot 45$, which could be halved by the use of proper spacers.

For teaching purposes, great care has to be taken in the choice of words and, for this reason, Mr Trimble's statement that "friction loss is independent of cable tension" should be modified, as this is evidently not the true meaning of his statement.

My own laboratory tests have confirmed Mr Trimble's findings, and relevant extracts may therefore be of interest.

Many experiments were carried out using a tubular duct $36 \mathrm{ft}$ long of sufficient strength to bear the compression, the compression being measured at $9 \mathrm{ft}$ intervals by strain gauges on the outside of the duct, while the cables were being jacked at one end.

The duct was of $\frac{3}{4}$ in. internal diameter and, among other tests, a comparison was made between the friction with six loose 0.2 in. diameter wires and with four 0.2 in. diameter wires threaded through holes in washers, using curves of various radii down to $15 \mathrm{ft}$. With the six loose wires, the coefficient of friction $\mu$ was 0.55 and the incidental friction $K$ was $0.2 \%$ per foot for a straight duct but smaller for a curved duct, the statistical result giving $K=0$. With the four wires with spacers at $1 \mathrm{ft}$ intervals, $\mu$ was 0.22 and $K$ was zero both for the straight duct and (statistically) for the curves of various radii.

Four tubes $9 \mathrm{ft}$ long were coupled by screwed unions carrying the strain gauges, and bent to the required radius and arranged to form a continuous curve, or a sinuous curve in four segments.

The extension measurements were omitted until attention was drawn to this omission* so only curves with radius of $50 \mathrm{ft}$ and less can be checked for extension. Also the comparison for continuous and sinuous curves was only made for curves of radius $50 \mathrm{ft}$ and greater.

The wires were $40 \mathrm{ft}$ long between anchorages and extended $2 \mathrm{ft}$ beyond the duct at the jack; another $2 \mathrm{ft}$ length had to be added along the ducts due to the couplings, at $9 \mathrm{ft}$ intervals, which carried the strain gauges.

*The work reported here was undertaken for one of the two theses required from each candidate for the B.Sc. degree at the University of Cape Town. 


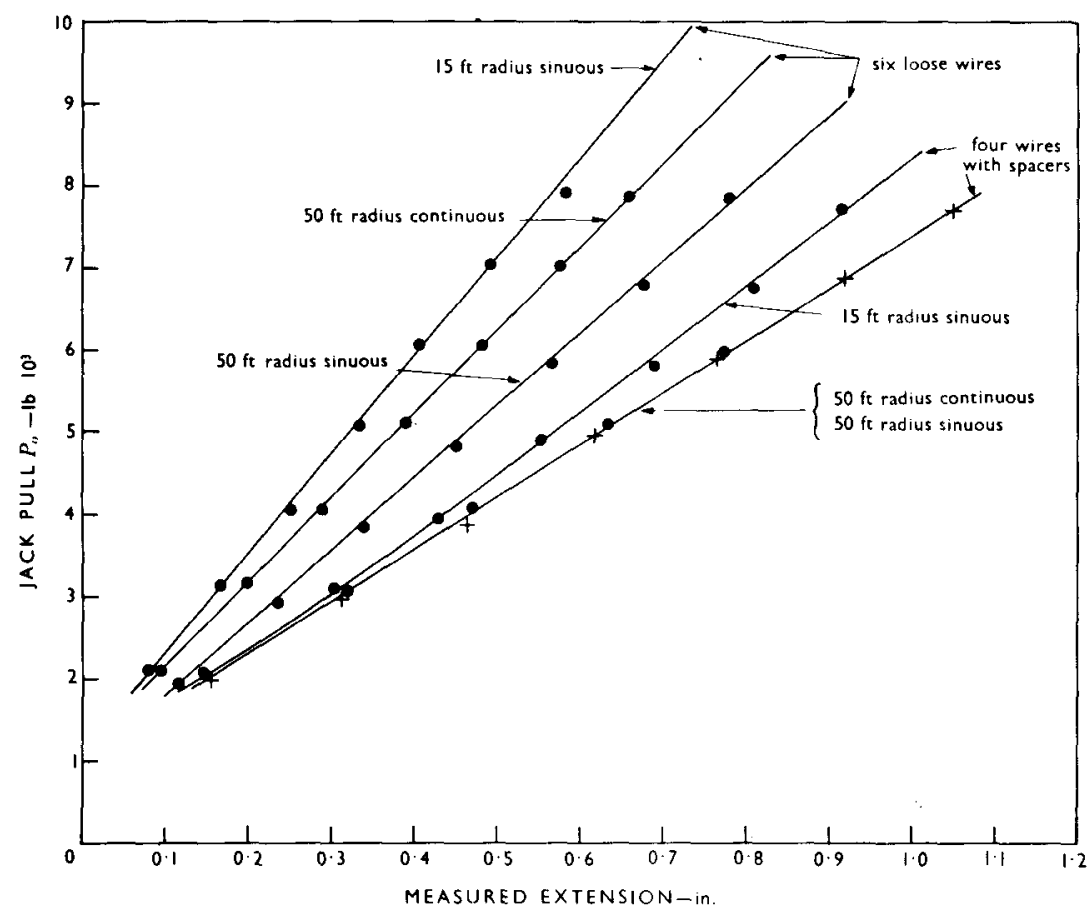

Figure I

The cross-sectional area of the material of the duct was $0.40 \mathrm{in}^{2}$ and of the wire $0.032 \mathrm{in}^{2}$. The value of $E_{s}$ was $29 \times 10^{6} \mathrm{lb} / \mathrm{in}^{2}$. The measured extensions at the jack are plotted in Figure I against the pull in the wires at the jacked end, $P_{o}$.

The friction coefficient $\gamma=\mu / R+K$ was found statistically from the tensions at five points along the duct for six different values of $\boldsymbol{P}_{o}$. The jack extensions, measured and calculated, and the ratios between them are given in Table I. The calculated extension was given by

$$
0 \cdot 12\left[2+\left(1-\varepsilon^{-3 \times \gamma}\right) / \gamma+A_{s}\left(1-\varepsilon^{-36 \gamma}\right) / 0 \cdot 4 \gamma\right] / 29 A_{s}
$$

The measured extensions were the same as those calculated, when proper spacers were used, and on the continuous curve even when spacers were not used. On sinuous curves and without any spacers, the measured extensions were 9 to $17 \%$ greater than those calculated and, according to my calculations, this agrees with $\mathrm{Mr}$ Trimble's findings. Would $\mathrm{Mr}$ Trimble give details of the spacer core he used and state whether it was examined after the test for collapse or displacement?

\section{Contribution by J. N. Lowe, M.A., A.M.I.C.E.} (The Pre-Stressed Concrete Co. Ltd)

There is a danger in paying too little attention to the effects of friction. When a member is prestressed the main aim is to apply a prestress which, when combined with stresses due to load, will result in acceptable stresses throughout the member, and yet is small enough to be acceptable alone.

The state of prestress is determined by the tendon force, the tendon profile and the position of the profile in relation to the member. Interest in these three factors is greatest at the moment before a tendon is grouted.

$\mathrm{Mr}$ Trimble emphasizes and supports Cooley's work in dealing particularly with the effects of the tendon profile upon the tendon force during stressing. Some of the results are disturbing; the agreement with Cooley's $32 \%$ compares with an average from 25.5 to $40 \%$ loss. Cable extensions are not helpful and there is no record of the extensions of different wires in a cable.

My main concern, however, is that $\mathrm{Mr}$ Trimble does not, in his conclusion, put in a plea for more investigation about what does happen and what can happen after the tendons have been extended but not grouted. My own experience leads me to believe that the final effect of friction is less or can be made less than that assumed by Cooley. For instance, tests to working load on beams made of precast sections with a joint in the middle, and with the ungrouted cable in a hole formed by Ductube, have not revealed early cracking-the cable force was there. There are, too, similar experiences with grouted cables. Five years ago I stressed a beam (almost identical with that described by $\mathrm{Mr}$ Trimble) by means of flat jacks which were placed in two gaps, each at points of 
contraflexure of the tendon, where the prestress was uniform over the section: measurements taken at the time indicated negligible friction.

If, then, Mr Trimble's evidence in support of Cooley is backed by others, it appears that our designs will be more expensive-and perhaps unjustifiably:

(1) steel must be chosen using the highest coefficient of friction-and so more steel will be required.

(2) concrete must be chosen using the lowest coefficient of friction-and so more concrete will be required.

I therefore submit the following suggestions.

(1) In design, should Cooley's figures indicate high friction loss, re-design with simpler tendon profiles, even with more numerous tendons. The cost per stressing operation will be reduced. The engineer will know his system of prestress within narrower limits.

(2) Again accepting Cooley's figures, examine the method of jacking the tendons. In the author's beams, for instance, jack from both ends or flat jack from intermediate points. This reduces friction losses and saves steel and concrete. The system of prestress is known within narrower limits.

(3) Remember that the prestress attributable to the profile shape and the force in the tendon along the profile may be most simply calculated for a constant tendon force, but it may be perfectly acceptable if the force in the tendon varies.

(4) Consider local over-stressing of a cable, probably at the ends.

It is also important during stressing to observe two rules.

(1) Move each tendon in its duct throughout its length, making sure that the force required does not exceed a given figure for the profile and duct lining.

(2) Make sure that readings are not taken from false zero-and yet avoid a stressing procedure which would confound the man on site.

For instance, take the gauge to, say, 1 load and check extension. Repeat at $\frac{1}{2}$ load. Produce the gauge and extension lines back to zero. Tally them and fix the zero. A very simple record card can be produced for this.

But while these measures will cater for present knowledge, and deal with Cooley's figures, more details are needed so that figures for friction and methods of overcoming it in design and on the site can be generally accepted as justifiable and the most economical.

We need to know how a tendon settles down after jacking. Cooley suggested this in his first report.

Tests are needed on singly, doubly or trebly curved ungrouted tendons to show the effect of:

(1) wedging the tendons;

(2) short-term movement of steel relative to concrete;

(3) applied vibration;

(4) long-term movements such as relaxation and creep.

Tests are also needed on beams with grouted and with ungrouted cables to show how they behave under working load, with varying friction losses assumed.

Engineering is a science of inequalities, and in this particular field of friction the limits are still too wide, with the emphasis of investigation on one limit only.

\section{Contribution by M. Henri A. P. Morris}

(Société Technique pour l'Utilisation de la

Précontrainte)

Mr Trimble is to be congratulated on an excellent experiment to determine the total friction along the length of a cable; the details have been well thought out, and some very interesting and useful results obtained.

Cooley's work and results are confirmed by those of Montagnon (1) and others, and it is true that the total losses can be quite accurately predicted using their methods. This is shown by $\mathrm{Mr}$ Trimble, but I feel that perhaps it is not made quite clear in the article. A calculated figure of $32.7 \%$ is given for the friction loss at the centre-line, but this, of course, is based on the assumption of the validity of the exponential relationship.

Now when the total percentage friction losses are plotted against the maximum tension, a rather large scatter is at once apparent (the results lie between 44 and $64 \%$ ). However, this is not quite so alarming as might at first appear. Let us assume the same variation of $\pm 10 \%$ from the mean in an actual structure. Now if it is remembered that some cables may thus be slightly over-stressed and others under-stressed, provided a reasonable figure can be obtained for the mean value of the frictional losses, then the actual total prestressing force should be very close indeed to the desired figure.

With this in mind, and also the uncertainty surrounding the various assumptions necessary in practical design and the difficulty of obtaining accurate values for the other losses, such as creep and relaxation, it would not be amiss to adopt a simplified formula in assessing the mean value of the friction loss. Such a simple formula, given below, is in fact commonly used in France today, and gives results believed to be accurate within a few per cent.

The percentage loss from a given initial tension is $0 \cdot 4(\alpha+n l) \%$ * where:

$\alpha$ is the total change in direction of the cable in degrees;

$l$ the length of cable in metres and

$n$ a constant representing the so-called line or wobble effect.

The usual figure for $n$ is close to unity. This applies to carefully placed cables of moderate curvature (i.e. with an angular change not exceeding, say, 30-40 ). An appropriate figure for cables having the fairly large angular changes of those tested would be about $1 \cdot 7$ to 2.0 . This depends, of course, on the known quality of the workmanship in placing and fixing cables, and on the radius of the curves. The tighter the curves, the higher the figure.

Some of this additional loss is possibly accounted for *This is not an empirical formula but is derived from the usual ex-
ponential type formula and has been verified experimentally on very many jobs. 


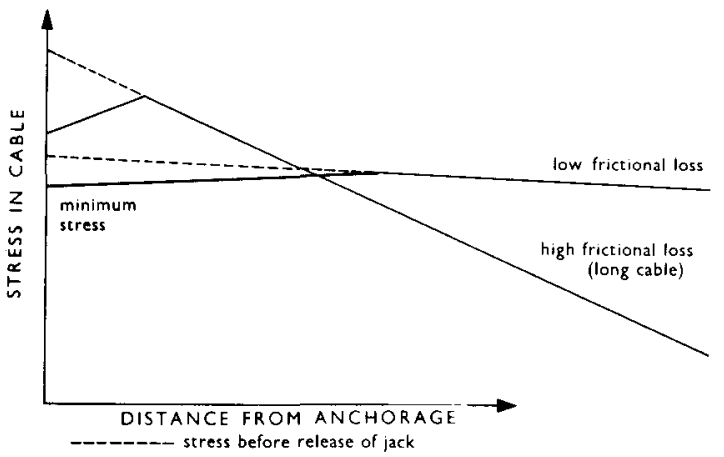

Figure II: Stress losses due to take-up of anchorage zone.

by inter-wire friction due to the partial collapse of the central helix. Hence we have: $0.4(107.5+2.0 \times 14.6)=$ $55 \%$, a figure which suits the facts very well.

Experience in the construction of reservoirs in France and elsewhere serves to confirm Mr Trimble's opinion that collapse of the central helix can and does occur with cables of large curvature. A simple calculation for a fully collapsed cable forming a complete circle indicates a possible additional elongation of about $4 \mathrm{~cm}$. Figures of this order have been encountered in practice and accordingly in such cases applied tensions are either measured directly, or from the pressure gauge. There is another fact to consider when this occurs; namely that the wires will be unequally tensioned. For cables of the usual length, this is not important, since the total applied tension will be the same and no individual wire is likely to be over-stressed but, in the case of short cables, there is the possibility of over-stressing individual wires and, accordingly, large curvatures in short cables should be avoided.

Mr Trimble's general observations on the effect of pull-in or take-up of the male cone on anchoring are quite correct, but it should be added that the minimum stress can also occur where frictional losses are low, e.g. for cables that are straight and horizontal, as indicated in Figures II and III.

\section{REFERENCE}

1. MONTAGNON, M. J. Aspects pratiques de la précontrainte par câbles. Le problème des frottements. Annales de l'Institut Technique du Bâtiment et des Travaux Publics. 1954. Vol. 7, No. 78. June. Béton Précontraint No. 19. pp. 503-520.

\section{Contribution by R. W. Hobbs}

(Ove Arup \& Partners)

The suggestion that extension measurements are not a reliable guide to the applied prestressing force in highly curved cables is obviously true, but extension measure-

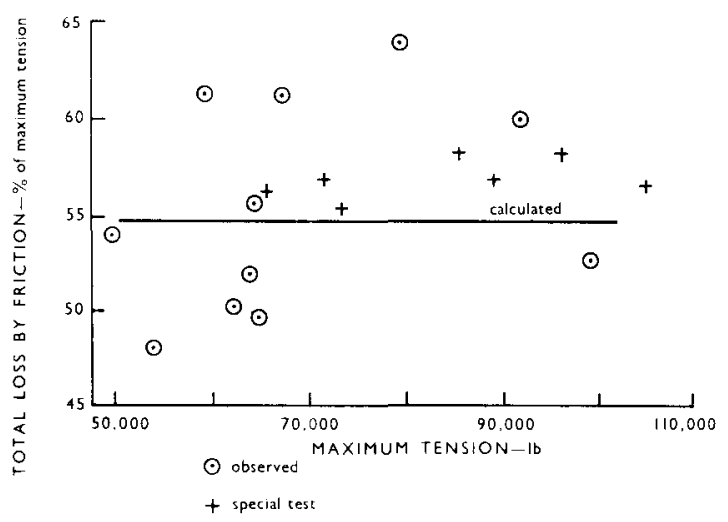

Figure III: Total friction losses.

ments will normaliy be the method used in practice for most cables; however, in curved cables, the amount of possible deformation can be calculated geometrically and, if this is a significant proportion of the total extension, then Mr Trimble's method of calibrating the jacks would prove useful.

The other suggestion put forward concerning the longitudinal distribution of force is interesting and appears to depend on the slope chosen for line 3 in Figure 4 of the text. This line could have a number of slopes, provided that they satisfied the condition that the area between it and line 2 represented the anchorage slip. I would like to know if there is any experimental evidence for the particular position of line 3 shown in Figure 4. In particular, have any measurements of strain on different parts of the cable been made? These could probably be taken by leaving windows to a cable near the surface of the concrete.

Contribution by E. H. Cooley, M.A.(Cantab.), A.M.I.C.E., A.M.I.Struct.E. (F. A. Macdonald \& Partners)

It is naturally gratifying to find that the friction losses calculated by Trimble for a number of highly curved Freyssinet cables agree closely with those predicted from the figures quoted in my paper.

Apart from the verification of my earlier work, Trimble's paper is extremely interesting in that it also throws light on the range of variation in friction loss to be expected in a series of similar cables. The extreme percentage friction losses quoted are 25.5 and 40.0 , with an average of $32 \cdot 7$, so that the maximum variations are $22 \%$ either side of the mean value. This also agrees closely with the figure of $20 \%$ suggested in my paper (1st edition, October 1953, page 22).

The comparatively large discrepancy between the measured and calculated cable extensions is a disturbing feature of the investigation, and it is hard to believe that this is entirely due to distortion of the cable during 
tensioning, as is suggested. I have observed a tendency for cables with reverse curvature to extend rather more than otherwise similar cables of single curvature, but this effect has not been pronounced. No figures are quoted in the paper to show the growth of extension with cable force at the jack for a particular cable and I should be pleased to hear whether such records were kept. It is possible that, with such highly curved cables, the initial cable force of $10,000 \mathrm{lb}$, at which the cables were marked for extension measurements, was insufficient to take up all the slack, particularly over the centre portion of the cables. This would be apparent from any non-linearity of the relation between cable extension and jack pressure.

It is not clear in Table 2 how the figures quoted for the calculated extension assuming no friction loss were determined for cables F14, G4, J16 and J6. In these cables, especially the last, the increase in cable force was not the same at each jack, a state of affairs that could not exist in a frictionless cable.

I note that a recommendation is made that extension measurements should not be relied on in determining the tension in a highly curved Freyssinet cable. As it is very rarely that a jack is properly calibrated by a method as comprehensive as that described in the paper, before use on a site, I should be pleased if the author could say whether the jack pressure gauges were at any time calibrated. Figure 3 shows that, for both jacks extending, the cable force is a measurable quantity while the gauge pressure reading is still zero. Allowing for the friction loss through the anchorage, which may exceed 5,000 lb cable tension, it would appear, therefore, that the pressure gauges employed by Trimble both possessed a zero error, possibly as high as $400 \mathrm{lb} / \mathrm{in}^{2}$.

\section{Reply by the author}

\section{MR JOHNS}

It is not clear how $\mathrm{Mr}$ Johns interprets the jack characteristics as confirming a friction loss in the jack and cone corresponding to a gauge reading of $200-300 \mathrm{lb} / \mathrm{in}^{2}$. For Jack B, both the characteristics (see page 96) show a negative zero reading clearly indicating a zero error in the gauge. For this and other reasons, I consider that where the jack is to be used to measure the force it is necessary first to calibrate the gauge or, preferably, the assembly including both jack and gauge.

I agree that no special precautions were taken during construction, but they were of course taken during tensioning, in that the jacks were calibrated to enable forces to be measured. This precaution appears to be necessary with cables subject to collapse if a reliable indication of the state of prestress is required.

I agree with Mr Johns that, even if a large part of the discrepancy between measured and calculated extensions were attributable to taking up slack, it would still be necessary to measure the cable force. I agree also that taking up slack is more difficult with treble than with single curvature. Some singly curved cables on the same

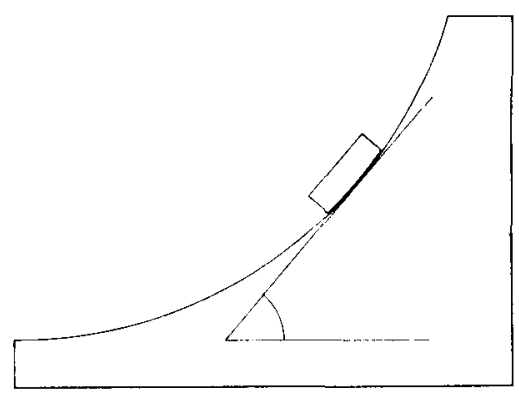

Figure IV: Condition of friction analogous to that in a cable immediately after stressing.

site, however, gave the following results:

$\begin{array}{ll}\text { Average measured extension } & 1.226 \mathrm{in} . \\ \text { Calculated extension } & 0.99 \mathrm{in} . \\ \text { Difference } & 0.236 \mathrm{in} . \\ \begin{array}{l}\text { Estimated difference for full } \\ \text { collapse (see M. Morris's }\end{array} & \\ \text { contribution) } & 0.262 \mathrm{in} .\end{array}$

The effect of " slack" in singly curved cables is probably small and the figures suggest that partial collapse occurred.

Mr Johns advances no factual evidence in support of the theory that variation in force along the cable is shortlived. It seems to me that the conditions in the cable immediately after anchoring are analogous to those of a block in a condition of limiting friction on a surface that is concave upwards as shown in Figure IV. Although the friction is limiting, any slight movement of either the block or the cable would result in a reduction of the force which caused the movement and the condition of both is therefore stable. It must be admitted that some movement of the cable and consequent redistribution of force can be expected to result from vibration, alternating flexure and temperature, creep and relaxation, but bearing in mind the inherent stability of the position of the cable after anchoring, this movement would surely take some months to develop and its magnitude would probably be limited.

If bonded cables were grouted within a few days of tensioning, the movement would be arrested before any significant redistribution of force could take place.

\section{PROFESSOR ROBERTSON}

I am very grateful to Professor Robertson for pointing out the error in Table 2 (see errata). The cables were stressed from both ends and the extension allowing for friction is therefore equal to the extension neglecting friction multiplied by a logarithmic function approximately equal to $\left(1-\frac{1}{2} \frac{p}{100}\right)$. As Professor Robertson suggests, this correction does not invalidate the arguments put forward in the paper.

Coiled wire spacers were used as Professor Robertson 
suggests but, as the cables formed part of a permanent structure, it was not possible to examine them after tensioning. In the advance estimate of losses the factors selected from Cooley's paper were $\mu=0.25$ and $K=10^{-3}$ and these gave reasonable agreement with the observed losses. The fact that the figure for $k$ is lower than Professor Robertson's figures may be due to the very thin coating of lead inside the duct acting as a lubricant. Alternatively, it may be due to the cables having been eased by moving them in the ducts before stressing commenced.

The results given in Professor Robertson's Table 1 are not strictly comparable with mine, as wire cores were not used by Professor Robertson. It may be interesting, however, to compare the range of the ratio of measured to calculated extensions. In Professor Robertson's tests on sinuous cables with no spacers, the ratio is between 1.09 and $1 \cdot 17$, and the average is $1 \cdot 12$; in my tests on sinuous cables with wire spacers, the range is 1.04 to $1 \cdot 34$, and the average is 1.20 ; but there is no observable correlation between this ratio and the percentage friction loss. The higher average figure is consistent with a partial collapse of the core during tensioning.

\section{MR LOWE}

With many of Mr Lowe's comments I agree, but I should like to make the following points.

(1) $\mathrm{Mr}$ Lowe suggests that there is evidence to support the theory that variation of force along the cable diminishes with time even in grouted cables. (An alternative interpretation of $\mathrm{Mr}$ Lowe's comments is that the redistribution takes place so quickly after tensioning that the force in the cable can be expected to be uniform along its length at the time of grouting.) Without numerical data regarding the cables he refers to, it is difficult for me to comment, but the fact that in a beam tested to destruction early cracking did not take place does not in itself confirm that the cable force was redistributed after tensioning. Figure 4 of my paper suggests that if the cable force became uniform throughout its length, this force would amount to about $74,000 \mathrm{lb}$. Since the predicted force, assuming no redistribution, is also $74,000 \mathrm{lb}$, the behaviour of the centre section under load would be much the same, and would therefore provide very little evidence either way.

Furthermore, although $\mathrm{Mr}$ Cooley suggested in his report that cables "settle down" after jacking, he informs me that observations made during the 8 months after jacking provided inconclusive evidence on this point. Mr Cooley shares my view that "settling down", if it occurs, would be confined to ungrouted cables. His longterm observations were made on cables specially left ungrouted.

(2) I agree that flat jacks can sometimes be used to reduce friction but they would have been difficult to use in this instance because the prestressed structure was integral both below and above with the frame of an eleven storey building (three further storeys are to be added at a later date).

(3) While I agree that friction losses entail heavier sections, it is not certain that the use of simpler or more numerous tendons would produce any saving in cost.

(4) Regarding the additional tests that $\mathrm{Mr}$ Lowe suggests, the figures quoted in my reply to $\mathrm{Mr}$ Hobbs provide some evidence regarding the effect of wedging the tendons, i.e. on "pull-in".

I believe that longitudinal vibration of tendons before anchoring has been successful in obtaining increased extensions and therefore reduced friction but with jacks that depend on wedges this process is at least potentially dangerous.

\section{MORRIS}

The figure of $4 \mathrm{~cm}$ extra extension quoted by $M$. Morris for total collapse on $360^{\circ}$ is equivalent to about $0.65 \mathrm{in}$. for the $150^{\circ}$ of the cables tested and this compares with an average difference between calculated and measured extensions of 0.426 in.

The observed figures are therefore consistent with partial collapse of the cables during stressing.

\section{MR HOBBS}

I have no direct evidence regarding the slope of line 3 in Figure 4 but there is some incidental evidence. The following test was carried out on a cable with no male cones.

(a) A determination of friction was carried out as with the other cables. The loss to the centre-line was $31 \cdot 2 \%$. (b) Both jacks were pumped to $106,000 \mathrm{lb}$.

(c) Both jacks were then pumped until an additional $\frac{3}{8}$ in. extension was produced at each end. The required forces were respectively $130,000 \mathrm{lb}$ and $131,000 \mathrm{lb}$.

(d) Jack pressures were released gradually until the extension at each end returned to its original value, i.e. the cable pulled in $\frac{3}{8}$ in. at each end. The jack forces were then $73,000 \mathrm{lb}$ and $68,500 \mathrm{lb}$. The fundamental difference, therefore, between this test and a normal stressing operation is that the forces were measured after movement equal to the usual " pull-in" had taken place.

The stressing history is represented in Figure $\mathrm{V}$ in which slopes correspond to a friction loss of $31.2 \%$ to the centre-line, the observed value for this cable.

The triangular areas in Figure $\mathrm{V}$ represent 0.382 in. and 0.316 in. which compare with 0.375 in. and, considering the accuracy of the test procedure, provide reasonable confirmation of the assumptions made in Figure 4 in deriving lines 3 and 5 from lines 2 and 4 . The comparison between the estimated anchoring forces in Figure 4, namely 70,000 and $74,000 \mathrm{lb}$, and the observed values of 68,500 and $73,000 \mathrm{lb}$ is also satisfactory.

I understand that Mr Cooley in his tests used "windows" left in the concrete and found no difficulty in taking the strain measurements on the exposed cables. In other investigations, however, difficulty has arisen from the redisposition of cable twist as the tension is applied and, furthermore, additional cost and inter- 


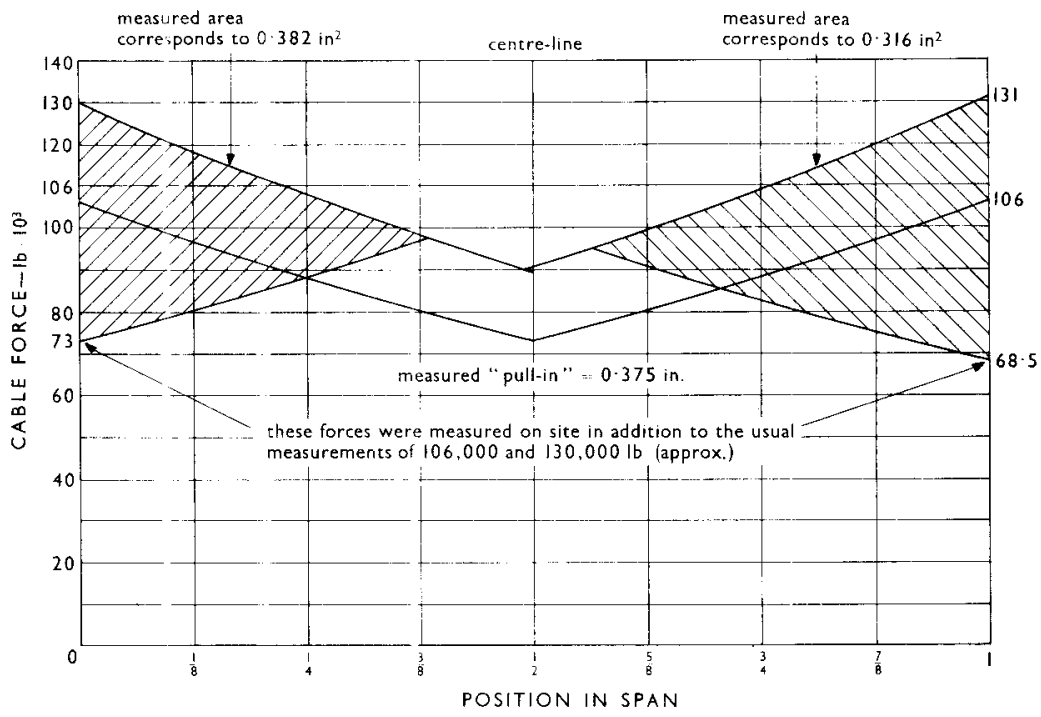

Figure V: Stress losses in a cable with no male cones.

ference with normal construction work cannot be disregarded. It was therefore decided to obtain as much information as possible from the ends of the cables only. An attempt was made to measure the cable strain during jack calibration by using an extensometer on the exposed cable between the blocks (see Figure 2) and even in this short straight cable the twisting during tensioning made strain measurement unreliable.

Professor Robertson's laboratory technique seems to overcome the difficulties and no doubt he will be able to throw some light on the question of variations of force along the cable and their duration.

\section{MR COOLEY}

Mr Cooley may regard the corrected discrepancies between measured and calculated extensions with rather less alarm. Unfortunately, no records were kept of growth of extension with cable force; I agree that this would have thrown some light on the " take-up " of slack which could be expected to occur before the distortion of the cable section takes place.

The extensions, assuming no friction loss, are based on the difference between the mean force finally and the mean force initially. It must be admitted that this procedure becomes rather artificial if the initial forces are unequal, but nevertheless it provides a useful standard of comparison.

The pressure gauges were calibrated immediately before the calibration of the jack-gauge assemblies and, as Mr Cooley deduces, were found to have substantial zero errors.

\section{SUMMARY}

(1) Mr Johns and Mr Lowe suggest that cable force may become redistributed very soon after the cables are anchored. I have given reasons why this seems to me to be unlikely and I understand that Mr Cooley's work in this connexion largely confims my views. Further experimental data would be useful.

(2) It is agreed that extension measurements do not provide a reliable indication of cable force when the cable is subject to collapse.

(3) Although it is generally agreed that cables with a helical wire core are subject to distortion or collapse, the discrepancy between calculated and measured extensions is attributed by Mr Johns, in part at least, to " takeup " of slack. The tests on the short singly curved cables where " take-up " would be small suggest, however, that collapse is probably more important.

(4) M. Morris confirms that "pull-in" can result in cable forces at the anchorages being lower than those elsewhere. Further confirmation is provided by the special test described in my reply to Mr Hobbs.

(5) Finally, although I consider that there is often insufficient evidence to enable the cable force to be determined accurately, I am by no means convinced that greater accuracy is always necessary. For example, if twothirds of the cables have only small curvature and only one-third are highly curved, the usual tensioning procedure in which the force is related to the measured extension should be sufficiently accurate. The ultimate moment of resistance is, after all, not greatly affected by even appreciable variations of prestress. 